\title{
Dairy farmer, hoof trimmer, and veterinarian perceptions of barriers and roles in lameness management
}

\author{
E. M. Wynands, ${ }^{1} \odot$ S. M. Roche, ${ }^{2} \odot$ G. Cramer, ${ }^{1 *}{ }^{*}$ and B. A. Ventura ${ }^{3} \odot$ \\ ${ }^{1}$ Department of Veterinary Population Medicine, University of Minnesota, St. Paul 55108 \\ ${ }^{2}$ ACER Consulting, Guelph, Ontario, Canada, N1G 5L3 \\ ${ }^{3}$ Department of Animal Science, University of Minnesota, St. Paul 55108
}

\begin{abstract}
Lameness is a leading animal welfare concern in the dairy industry. Multiple stakeholders are involved in lameness management on a dairy farm, including farmers, hoof trimmers, and veterinarians. This study sought to explore perceptions of lameness, perceptions of roles in lameness management, and barriers to improved lameness management in these groups. Fourteen homogeneous focus groups were held in Minnesota, Wisconsin, and New York from April 2017 to March 2020; 5 with farmers $(\mathrm{n}=31), 4$ with hoof trimmers $(\mathrm{n}=32)$, and 5 with veterinarians $(\mathrm{n}=25)$. The 1 -h facilitated discussions were audio-recorded, transcribed verbatim, and common themes identified through thematic analysis. Lameness was perceived by participants as a complex health problem and one in which the connections between pathogenesis, facilities, and management were not always well understood or easy to change. The complexity of the problem encompassed the lack of agreement on a definition of lameness, normalization to its signs, and the interconnectedness of lameness with other health and management issues. These issues appeared to contribute to resignation by participants that lameness was inevitable. Despite shared concerns about lameness among these groups, respondents reported a lack of communication, especially between hoof trimmers and veterinarians. Participants also voiced a desire to work together more productively, with hoof trimmers and veterinarians valuing the ability to deliver a consistent message to farmers. These findings suggest a need for increased efforts to facilitate collaboration between farmers, hoof trimmers, and veterinarians to improve lameness management on dairy farms.
\end{abstract}

Key words: attitude, stakeholder engagement, focus group, cattle welfare, communication

Received April 13, 2021

Accepted July 13, 2021.

*Corresponding author: gcramer@umn.edu

\section{INTRODUCTION}

Lameness is the clinical presentation of impaired locomotion and is caused by a range of foot and leg conditions, the most common of which are hoof lesions caused by infectious agents or internal and external forces (Murray et al., 1996). Lameness is a leading animal welfare concern in the dairy industry (Ventura et al., 2015). Lameness also has substantive economic repercussions (Dolecheck and Bewley, 2018), as productivity is decreased through reduced reproductive efficiency (Bicalho et al., 2007) and milk production (Archer et al., 2010) and increased culling (Booth et al., 2004). Various best management practices for preventing lameness (Bell et al., 2009; Main et al., 2012) and treating lame cows have been developed (Groenevelt et al., 2014; Thomas et al., 2015). Despite this growing knowledge, lameness persists as an industry problem; for example, a survey of large Wisconsin dairy herds estimated the prevalence of lameness at $13 \%$ with a range of 3 to $36 \%$ (Cook et al., 2016), and von Keyserlingk et al. (2012) showed a lameness prevalence of $55 \%$ with a range from 12 to $80 \%$ in northeastern US freestall herds.

Increasingly, there has been an interest in understanding the psychology and experiences of key stakeholders (people with an interest or concern in a system or organization; Bryson, 2004), as they choose to adopt or recommend disease management strategies on dairy farms (Ritter et al., 2017; Sumner et al., 2020). The most meticulous disease control and prevention strategies are of little use if stakeholders do not implement or support them. Therefore, it is important to understand the barriers faced by farmers and farm advisors as they make cow health and welfare decisions. This knowledge can help guide our research, interventions, and communications within the area of lameness management so our work can better resonate with stakeholders working on farms.

There are many important stakeholders in lameness management, including farmers, hoof trimmers, and 
veterinarians. Farmers ultimately make the management, financial, and ethical decisions for their farms (Driessen, 2012) and researchers are increasingly directing attention to farmer motivations and barriers in lameness management. For example, Leach et al. (2010) found that farmers were motivated by the pain and suffering of lame cows and pride in a healthy herd, and that farmers reported lack of time and labor as important barriers to implementing lameness management practices. Other reported barriers included a lack of necessary equipment, knowledge, or training (Dutton-Regester et al., 2019).

Veterinarians and hoof trimmers are also of interest for understanding lameness management, as they often take on advisory or supportive roles. Veterinarians provide information on all aspects of animal health and are often key advisors in health management programs (LeBlanc et al., 2006). As the understanding of health and welfare broadens, veterinarians are no longer alone in providing expertise and advice. In 2013, 88.6\% of US dairy herds surveyed performed some degree of hoof trimming, with a professional hoof trimmer employed in $80.2 \%$ of those herds (USDA, 2018). Croyle et al. (2019) found farmer participants in their focus group study viewed hoof trimmers as a source of lameness management advice, in addition to providing hoof care services. However, despite their importance, little information exists about hoof trimmers' perceptions of their work and contributions to lameness management. To our knowledge, just 2 studies have included any focus on hoof trimmers in North America, one which surveyed their lameness treatment practices (Kleinhenz et al., 2014) and another which focused on billing practices (Dolecheck et al., 2018). These studies explored hoof trimmers' selected therapies for lesions and costs of specific treatments, but we still lack a clear understanding of hoof trimmers' experiences as stakeholders in lameness management.

Lameness has multiple causes and areas of management concern, including but not limited to hoof horn health, infection pressure, forces on the feet, and early detection and treatment (Hulsen, 2011). Due to the multiple factors involved, implementing a management change can often involve collaboration between farmers and farm advisors, each of whom may have unique and overlapping roles. There is some evidence to support that lameness can be managed more successfully in consultation with advisors. For example, Whay et al. (2012) found farmers implemented more changes likely to positively affect lameness when the ideas were generated with the direction of a veterinarian rather than on their own. Similarly, the reduction of lameness over time was greater on farms that were monitored and offered additional support from researcher and vet- erinarian stakeholders compared with farms that only received monitoring (Main et al., 2012).

As the importance of talking to stakeholders and understanding the beliefs that influence their decisions becomes clearer, information is still lacking on how some of these individuals perceive lameness management and navigate challenges in their own roles and in collaboration with others. Therefore, the objective of this study was to use focus groups to explore dairy farmers', hoof trimmers', and veterinarians' perceptions of barriers to lameness management. Specifically, we sought to identify stakeholder perceptions of lameness, perceptions of their own roles in lameness management, and their expectations of these other stakeholders.

\section{MATERIALS AND METHODS}

This study was approved as exempt from review (study number 1702P08721) by the University of Minnesota Institutional Review Board.

\section{Positionality Statement}

Positionality refers to an individual's worldview and the position they adopt within a research study (Holmes, 2020). This statement provides transparency in how our interests, beliefs, and experiences may influence our analysis. E. Wynands is a researcher in dairy cattle health management and welfare. She grew up on a dairy farm and she has worked with farmers, hoof trimmers, and veterinarians in the area of lameness management but is not a farmer, hoof trimmer, or veterinarian herself. She carried out this study as part of her $\mathrm{PhD}$ research and the other authors are part of her $\mathrm{PhD}$ advisory committee. S. Roche is an animal scientist with an interest in dairy cattle health and welfare, and a consultant who works closely with farmer, veterinarian, and other farm advisory organizations internationally. G. Cramer previously owned and operated a dairy farm and a lameness specific veterinary practice; he is now a researcher in dairy health management and a veterinarian specializing in foot health. B. Ventura is neither a farmer, veterinarian, nor dairy advisor; she is an animal scientist with an interest in animal welfare and stakeholder communication. All authors entered into this research with an interest in dairy cow welfare and approached this topic with the understanding that these stakeholders are experts at what they do and that we can learn from their lived experiences.

\section{Study Design}

People weigh decisions based on a complex array of their circumstances, beliefs, and goals (Ajzen, 1991) 
and qualitative methods are often used to explore the factors influencing decisions and behaviors (Berkwits and Inui, 1998). A focus group methodology allows for an open discussion to explore a range of perceptions and experiences, both from the individual and from the group (Krueger and Casey, 2015). Focus groups have been used to understand farmer motivations in udder health management (Shock et al., 2020), Johne's disease (Roche et al., 2019), and expectations for animal welfare advice (Croyle et al., 2019). We used a multiple-category design (Krueger and Casey, 2015) to capture the experiences of our different stakeholder groups. This strategy entails conducting focus groups with several types of participants, allowing for comparisons within categories (e.g., farmers with small herds to farmers with large herds) and from one category to another (e.g., comparing farmers to veterinarians). Focus groups were kept homogeneous with respect to stakeholder category (farmer, veterinarian, hoof trimmer), as these individuals have different roles in lameness management and discussions are easier among people who have shared experiences (Krueger and Casey, 2015). We framed lameness as a challenge for stakeholders and used a critical realist perspective to understand the complexity and context in lameness management decisions (Maxwell, 2012). Critical realism is an integration of the acknowledgment that a real world exists and our understanding of the world is constructed through our perspective and worldview (Maxwell, 2012). Within this perspective, we did not intend the results to be generalizable as defined within the positivist paradigm (Denzin and Lincoln, 2000).

\section{Participant Recruitment}

Though this study did not aim to be representative of the stakeholder population, we include the following as context about the populations from which the participants were drawn. Minnesota (MN) and Wisconsin (WI) have a high density of dairy farms and were therefore the region of interest for this study. There were 2,325 dairy farms in MN (MDA, 2021) and 6,932 in WI (USDA, 2021) as of January 1, 2021, and the majority of milking cows are housed inside yearround. The number of hoof trimmers in $\mathrm{MN}$ and WI is not known, but the majority of dairy farms use a professional hoof trimmer (USDA, 2018). Likewise, the number of veterinarians in dairy practice is unknown, though this can be approximated by membership data from the professional organization American Association of Bovine Practitioners. As of January 20, 2021, there were 156 registered members in $\mathrm{MN}$ and 345 registered in WI, though these members include veterinar- ians not in dairy practice. The majority of dairy farms in the United States are registered with National Dairy FARM Program Animal Care, including 98\% of dairy farms in MN and $95 \%$ of dairy farms in WI (National Dairy FARM Program, 2021). This program requires a minimum level of veterinary involvement on dairy farms.

We conducted 14 focus groups between April 2017 and March 2020: 5 with farmers, 4 with hoof trimmers, and 5 with veterinarians. To be eligible for recruitment, farmers had to be the owner or manager of a dairy farm, hoof trimmers had to be full-time commercial hoof trimmers, and veterinarians had to be full-time practitioners working primarily in dairy practice. The recruitment process, location, and general focus group characteristics are presented in Table 1. Focus groups were held in MN, WI, and New York (NY). Most focus groups were held at existing conferences or meetings $(\mathrm{n}=9)$ and we recruited participants from meeting attendees. Focus groups were advertised via email before the meetings and included in meeting agendas. We also contacted hoof trimmers and veterinarians through professional networks to invite them to a workshop on lameness management ( $\mathrm{n}=3$ focus groups). We held the focus groups before presenting the workshop content. Finally, we also recruited individual dairy-focused veterinary clinics through professional contacts and held a group with all the veterinarians in that clinic ( $\mathrm{n}=2$ focus groups). All participants were paid an honorarium of $\$ 50$ for their participation. We sought for a range of 4 to 8 participants per group based on recommendations for thematic analysis using focus group data (Clarke and Braun, 2013).

\section{Data Collection}

We developed and pre-tested a questioning guide before data collection with small groups of hoof trimmers, veterinarians, and veterinary students. The questioning guide was composed of a series of open-ended questions and follow-up probing questions (Appendix). Questions focused on eliciting participants' attitudes toward and perceptions of lameness, challenges, or barriers they faced in lameness prevention and treatment, and their view of their own and other stakeholders' role in lameness management. Participants were also asked about their experiences with lameness extension programs and what they would need or want from an extension program (responses from these questions are not presented in this paper). Question wording was adjusted slightly depending on the respective stakeholder group. Before the discussion, participants were briefed on the aims of the project and consented to participating. 
Table 1. Focus group stakeholder category, meeting type, and date for 14 focus groups: 5 with farmers, 4 with hoof trimmers, and 5 with veterinarians $^{1}$

\begin{tabular}{|c|c|c|c|c|c|}
\hline Stakeholder category & State & Event type & $\begin{array}{c}\text { No. of } \\
\text { participants }\end{array}$ & Date & $\begin{array}{c}\text { Length } \\
\text { (min) }\end{array}$ \\
\hline Veterinarian & $\mathrm{MN}$ & Regional conference & 5 & Apr 2017 & 80 \\
\hline Veterinarian & $\mathrm{MN}$ & Regional conference & 6 & Feb 2018 & 54 \\
\hline Veterinarian & WI & Veterinary clinic & 5 & Jan 2020 & 56 \\
\hline Veterinarian & MN & Workshop & 6 & Jan 2020 & 71 \\
\hline Hoof trimmer & NY & National conference & 7 & July 2017 & 86 \\
\hline Hoof trimmer & WI & Workshop & 8 & Jan 2020 & 67 \\
\hline Farmer & $\mathrm{MN}$ & Regional conference & 5 & Nov 2018 & 66 \\
\hline Farmer & $\mathrm{MN}$ & Regional meeting & 11 & Feb 2019 & 54 \\
\hline Farmer & $\mathrm{MN}$ & Regional meeting & 4 & Feb 2019 & 53 \\
\hline Farmer & $\mathrm{MN}$ & Regional meeting & 7 & Feb 2020 & 46 \\
\hline Farmer & $\mathrm{MN}$ & Regional meeting & 4 & Mar 2020 & 55 \\
\hline
\end{tabular}

${ }^{1}$ Focus groups were held in Minnesota, Wisconsin, and New York from April 2017 to March 2020.

${ }^{2}$ Includes 2 veterinarian participants who attended a previous group.

All focus groups took place in quiet, private locations and lasted approximately 1 to $2 \mathrm{~h}$. A single trained facilitator (EW) moderated all focus group discussions. Immediately following each focus group, the facilitator wrote memos to capture group dynamics and key impressions (Birks et al., 2008). All focus groups were digitally audio-recorded and transcribed verbatim by a professional transcription service.

\section{Data Analysis}

Following transcription, transcripts were checked for accuracy against the original audio by the first author (EW). Thematic analysis, a qualitative methodology used to identify, analyze, and report patterns in written data, was used to analyze the transcripts (Braun and Clarke, 2006). The first author (EW) read and re-read the transcripts and made initial notes, labels, and reflective memos. The transcripts were then coded inductively, a process of assigning labels and categorizing content. Initial codes were discussed with other authors (BV, SR, GC) and refined. Throughout the process, we worked on one stakeholder group at a time (e.g., coding only the veterinarian transcripts before moving on to the hoof trimmer transcripts). Once initial codes were developed for each stakeholder group, we then considered all the stakeholders together and searched for similarities and differences in the codes. We were interested in where the experiences of stakeholders overlapped and where they were unique. EW, in consultation with BV and SR, then organized the codes into broader themes. The themes were then checked across the transcripts to evaluate their depth and robustness. After reflecting on the initial themes through the transcripts, EW, SR, and BV decided on the final themes and written theme descriptions. Throughout the analysis, EW wrote memos to explore and reflect on the data. All labeling and coding was done using the program Quirkos (Quirkos Ltd.).

Quotations are presented below as examples of the themes and to incorporate the participants' own voices when describing them. Ellipses indicate where text was omitted, square brackets indicate the authors' additions for clarity, and quotations are labeled by participant ID. The letter indicates the focus group and the number indicates the participant (e.g., veterinarian B3 was participant 3 from veterinarian focus group B).

\section{RESULTS}

Focus group interviews ranged in length from 46 to 86 min (median length $=61 \mathrm{~min}$ ). In total, 31 farmers participated, all based in MN, with tiestall or freestall barns and herd sizes ranging from 28 milking cows to 1,200 (median size $=100$ cows). Twenty-four farmers identified as men and 7 as women, ranging in age from 27 to $77 \mathrm{yr}($ median age $=51 \mathrm{yr})$. The median number of years dairy farming was 30 (range of 5-55 yr). We had 32 hoof trimmer participants with an age range of 22 to $73 \mathrm{yr}$ (median age $=40 \mathrm{yr}$ ), all men. Eleven hoof trimmers were from MN, 9 WI, 2 Idaho, 2 Michigan, 1 Pennsylvania, 1 NY, 1 Georgia, 1 Ohio, 1 Connecticut, and 2 unknown. The median number of years hoof trimming was 16 (range of 1-47 yr). Last, 25 veterinarians participated (17 men, 8 women) aged 26 to $66 \mathrm{yr}$ (median age $=43 \mathrm{yr}$ ). Eighteen practiced in MN, 5 in WI, 1 in Colorado, and 1 in Iowa. The median number of years in practice was 18 (range of 1-41 yr). 

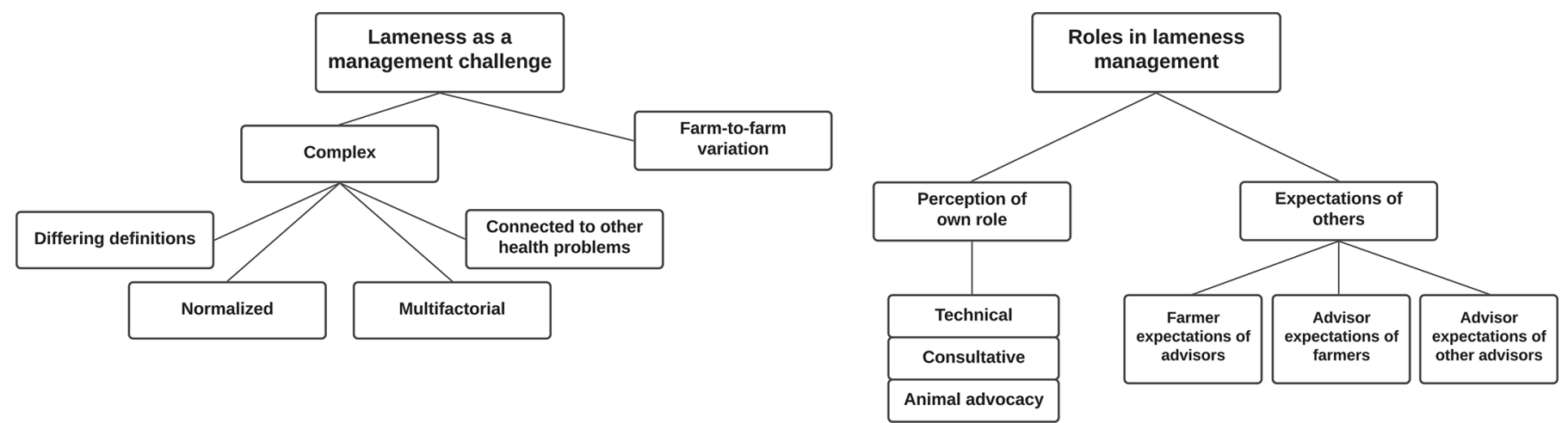

Figure 1. Thematic map outlining the themes and subthemes of thematic analysis generated from 14 focus groups: 5 with farmers, 4 with hoof trimmers, and 5 with veterinarians. Focus groups were held in Minnesota, Wisconsin, and New York from April 2017 to March 2020.

\section{Thematic Analysis}

Themes were organized around 2 questions: what are the primary barriers in lameness management? (theme 1); and what are the barriers and motivators in lameness management related to roles and expectations of others? (theme 2). Theme 1 provides a descriptive framing of participants' views toward lameness as a management challenge (subthemes: lameness as complex, farm-to-farm variation), whereas theme 2 captured stakeholders' role in lameness management (subthemes: perception of own role, expectations of others). Figure 1 provides a thematic map depicting the themes, subthemes, and relationships. In our thematic analysis, there was substantial overlap between hoof trimmers and veterinarians as they share a role as farm advisors; therefore, when a subtheme explanation is relevant to both hoof trimmers and veterinarians, we describe them as farm advisors.

\section{Theme 1: Lameness as a Management Challenge}

Lameness was acknowledged as an important, critical challenge by all stakeholder groups. Participants focused on a few specific conditions: white line lesions, sole ulcers, abscesses, foot rot, and digital dermatitis. The most commonly discussed lesion was digital dermatitis; for example, farmer D7 said, "If it wasn't for hairy warts [digital dermatitis], I don't think it would be as big of a problem." Regardless of condition, stakeholders worried about lameness due to its economic significance. For example, participants noted the cost of preventative measures: "They can spend as much on hoof products as they do on veterinary products total. Easy. Or more...that's a hell of a lot of money" (veterinarian B2). Participants also discussed the economic impact of production losses from lame cows, as hoof trimmer D6 said, "It's like-you're seeing the cost of us trimming it, but what you're not seeing is the milk loss and the unhealthy cow, and you end up shipping her; it's the long-term costs that you're losing." The time and labor involved in lameness management were also a concern as described by veterinarian A2 as they worked to solve a lameness issue on a farm: "It takes a lot of time and a lot of effort." Similarly, farmer A4 shared, "...[I] pretty much do all the work myself. Time is an issue." Though discussed less frequently, lameness was also viewed by some participants as important due to the cow being in pain and the subsequent impact on cow welfare. For example, hoof trimmer C1 said, “...this cow is living in pain to put milk in your bulk tank. It ain't right," whereas veterinarian E5 explained, "I tell them [farmers] lameness is, if not number one, it's getting there as far as welfare concern in the industry and that this is something they need to pay attention to."

Lameness as Complex. Lameness was viewed by participants as a complex management challenge, perceived differently by different stakeholders, and one in which the connections between pathogenesis, facilities, and management were not always well understood or easy to change. The complexity stemmed from several different factors, including the lack of agreement on a definition of lameness, normalization to the signs of lameness, the interconnectedness of lameness with other health and management issues, and the multifactorial nature of lameness, which ultimately appeared to contribute to resignation by participants that lameness was inevitable.

Differing Definitions. Participants described having differing definitions of lameness and what signs constituted a lame cow, particularly between advisors and farmers. Hoof trimmers expressed picking up on more subtle signs of lameness than the farmers they worked with. For example, hoof trimmer D7 said, "It's getting on the same page on the definition of lameness, some people are a little bit too loose with the term that 
it's - a lame cow is not a cow that won't get up. A cow that won't get up is a dead cow. A cow that you can tell she's uncomfortable on her feet or she's dancing a lot, her balance is off, bruising. There's wide variation of lameness that a lot of people don't recognize as lameness."

Normalized. Veterinarians and hoof trimmers agreed that farmers did not always notice the lame cows in their own herds and that lameness could become commonplace or normalized. Hoof trimmer D1 commented, "They get used to it. They get used to seeing it," whereas veterinarian E5 stated, "But with lameness, I think they've just gotten used to seeing it and haven't maybe appreciated the big deal that it really is." As outside observers to the farm, advisors felt it was easier for them to notice lame cows; for example, hoof trimmer A3 said, "...it takes lameness a lot longer to develop and it's so incremental...unless you're new eyes coming onto the place looking around...everyone else thinks it's business as usual."

Connected to Other Health Problems. Lameness was also viewed as complex because of its close relationship to other health problems. Participants viewed lameness as a risk factor for other diseases. Farmer A3 said, "Many times I'll have a fresh cow that has a twisted stomach. You go look at her and, oh, she has a sore foot, or you got a cow that's not expressing heat. Well, she's got a sore foot...so much of the time, it's the underlying factor for a lot of other health issues I guess I see on my farm." Lameness was seen as a cause of subsequent metabolic or production issues, since a cow who cannot move easily will struggle on the farm, as voiced by farmer E4, "Lameness probably dictates your metabolic issues, your mastitis, your repro[duction], everything. So, [she] can't get up and eat, [which] starts the whole thing."

Advisors described lameness as multifactorial, with the causes and solutions not readily apparent. Veterinarian A5 said, "If you have $15 \%$ of cows that have some level of ambulation trouble, why? Maybe it's one thing. Maybe it's three. You don't know." Participants acknowledged that there are many facility, management, and farmer decisions that contribute to lameness on a farm. Hoof trimmer B4 said, "...you have a farm that is focused on cow comfort, cow care, and healthy animals, or you have a farm saying we need the dollars, we're going to cram them in there, we're going to pack them through. So the variables are the key thing." Veterinarians were particularly frustrated by the multifactorial nature of lameness and the lack of simple answers to give to clients. For example, veterinarian E4 said, "... when you can't give a farmer a straight answer...when you can't just say, 'This is the answer, boom,' they're like, 'I'm not wasting my time.' So how do you try to convince them that the latest research is the way to go at the moment?"

The complexity of lameness and the management challenges presented also appeared to contribute to a feeling of resignation among farmers, as farmer E4 shared, "Yeah, I believe it's the number one issue on the farm. Because if you've got concrete, you've got lameness and there's no way around it. How do you manage it? No idea." Frustration that lameness management was an endless burden was a common theme, captured by farmer B1's lament: "I mean all we're doing is repetitiveness with treating and treating and treating and treating. Treating and trimming and treating and trimming, but unless you can make them that their hooves don't grow...that's it."

Farm-to-Farm Variation. Advisors agreed there was a great deal of variation among farms, with some struggling with lameness and some managing it successfully. Hoof trimmer B1 said, "It varies on the farm, it varies on the producer. Lameness can be a very intense problem at one dairy and two miles down the road it's a non-issue. So there are so many variables." Advisors saw several reasons for variation among farms, including farm facilities and farmer mindset. For example, veterinarian E2 said, "...new facilities have decreased lameness, but it's still an individual thing, how they pay attention to it. We can go to brand new barns and find one guy that just has a horrid problem with it, but he can ignore it. And then we can-the other guy who's in tune to it, he can have less facilities and still manage it much better. I don't know if it's-lameness is kind of like manure. It can pile up or it can get hauled out [laughter], for lack of a better description." Advisors also saw the prioritization of lameness by farmers as an important factor. Hoof trimmer D5 said, “... the producer needs to take a lot of responsibility to keep those feet in check." Some farmers also noted the variation; for example, farmer B10 said, "Some places have absolutely nothing and the next place is the same situation and full blown," but most spoke about their own farms and their own experiences.

\section{Theme 2: Role in Lameness Management}

Overall, no single experience of lameness emerged from the discussions; rather, advisors and farmers shared that farms experienced lameness management differently depending on a variety of internal and external factors. Throughout the discussions, participants highlighted how multiple people have a role in lameness management and that lameness management is a shared responsibility.

Farm advisors (hoof trimmers and veterinarians) discussed their role in lameness management as 3-fold, 
encompassing the day-to-day farm level technical work and management, a consultative role that was more people focused, and a role in advocating for the welfare of the cows.

Advisors: Technical Role. The technical work for hoof trimmers consisted of maintenance trimming, treating lesions, and record keeping, as described by hoof trimmer A5, "I always think there are three I's to hoof trimming: identify the cow; investigate; induce treatment." Most hoof trimmers viewed maintenance trimming as an important part of their role in preventing lameness; for example, hoof trimmer D5 said, "For me, I run a really strict protocol for maintenance, and I won't trim for a farm that doesn't want to do strict maintenance because I don't want to be using a lot of blocks. I don't want lameness on my herds, and it's much easier to just go trim and not repair."

For veterinarians, the technical role varied from treating individual cows, to monitoring footbath practices, to looking for lame cows while at the farm doing other tasks. For example, veterinarian E3 said, "...for a handful of those smaller clients, it's still to come out to the barn and pick up the foot and clean it up, open the abscess, and put a block on it." Veterinarian C1 said, "Verifying foot bath protocols. Making sure they're still doing what they were doing last month or six months ago. Checking products."

Advisors: Consultative Role. In their consultative roles, advisors shared how they discussed prevention strategies, assisted with goal setting, provided education, and monitored data. This consultative role was people focused, with advisors describing their efforts to initiate discussion on lameness management or answer farmer questions. For example, veterinarian D2 shared, "I think at a base level, we do walk pens frequently so to identify severely lame cows. But, then, also to have a discussion about why those cows are there. And what might be done about the fact that there are lame cows," whereas veterinarian E1 said, "I think we have a role too as far as educating how lameness occurs." Hoof trimmer comments echoed this people-focused role, as hoof trimmer D5 said, "And like [D7] said it, identifying other stuff, not just being the hoof trimmer, but the hoof care professional for the farm. Identifying, coaching them, opening their eyes to anything that could help them potentially make more money or be more efficient."

Advisors: Animal Advocate Role. Finally, some advisors were very explicit in describing themselves as advocates for the animals. For these individuals, this role involved pushing for lameness treatments and prevention to improve the welfare of the cows on the farms they worked with. Veterinarian A4 said, "... the most important role for the veterinarian [is] being the animal welfare advocate," while veterinarian B5 shared, "You don't just leave them be until the hoof trimmer [arrives]...In reality, that is not very humane and I think we need to instill some cow-care in these animals."

A few hoof trimmers similarly raised this theme; for example, hoof trimmer D5 said, "Yeah, the animal welfare. I've told some farms. I said if these were dogs, you'd be in prison. If you had a dog get this bad, somebody got a picture of that, you go to jail for that. And I know that's pushy and that's risking getting pushed right off that farm, but on the same hand, somebody's got to speak for the cows. They can't speak for themselves."

At the same time, advisors also acknowledged the limits of their role in resolving lameness. Hoof trimmers, for example, noted that they alone are not the solution to lameness, as stated by hoof trimmer C4: "I think we all need to keep in mind that some guys put too much pressure on themselves to be the sole solution for lameness. I think we have got to keep in mind that that's not possible, not feasible. We need to see it's a whole industry collaboration to improve it. Not just us." Meanwhile, veterinarians acknowledged being faced with limitations on their time and attention (i.e., needing to serve other roles) and that they often were peripheral in importance compared with hoof trimmers, as voiced by veterinarian D4: “...there's so many other things that we're focusing on when we're on a farm or trying to help manage at the farm or help the herdsmen manage their farm...lameness kind of falls to the sideway." This issue was echoed by veterinarian B2: "Now they have somebody to take care of the acutely lame cows, the chronic-lame cows, the routine hoof trimming well, what's left? ... Once again, as many things in veterinary medicine, we hand off these problems to other people, right? That's okay, but then sometimes it's difficult to get back in that loop."

Farmers. In contrast to the relatively lengthy time spent in discussion of advisors' own perceived roles in lameness, farmers spent less time articulating their roles. For example, farmer D3 stated their role in lameness management was to "identify and fix." Generally, farmers envisioned their role as one composed of daily tasks and took ownership and responsibility for the health of their cows, as captured by farmer A1, "I'm the one who gets to fix them," and farmer D5, "Do what I can to help her out - alleviate the pain."

Similar to their advisors, farmers also discussed their role as technical and people focused. Technical tasks included observing cows, treating lame cows, running footbaths, and organizing lists, whereas people-focused roles included employee management and consulting advisors. For example, farmer E4 said, "When you're 
walking, does it feel right? If it's slippery, make it a big deal. Hey there's something wrong here, let's make sure we mark that to get it grooved up more. So that's our role, is just prevention, prevention, prevention." Farmers also managed scheduling herd visits with advisors and sought counsel from advisors. For example, farmer D3 said, "Call the hoof trimmer and schedule him to come and identify our - and sort the cows off that need to be trimmed or worked on."

\section{Expectations of Others}

Farmers' Expectations of Advisors. Farmers often viewed the role of hoof trimmers and veterinarians in lameness management as being different, and seemed to look much more to hoof trimmers for lameness support. For example, farmer E4 said, "I just put more emphasis on the hoof trimmer. That's their problem and their responsibility." Farmers relied on the hoof trimmer to be another set of eyes and expected hoof trimmers to make connections between hoof issues and herd-level changes. Farmer A4 said, "He or she [the hoof trimmer] also should see what patterns they see across the herd or changes from the last month they were there or season they were there or whatever. It shouldn't just be fixing cows and leaving the farm and see you next time. It's got to be-we expect more than that from our employees."

Though some farmers valued the veterinarian in investigating herd-level issues (e.g., as farmer A3 said, "I think a good vet can help spot issues and reasons why you are having problems and help you with that more than fixing feet"), farmers more commonly voiced that they found veterinarians to play a limited role in lameness management. As farmer B2 expressed, "Most of the vets I deal with, he'll tell you get a hoof trimmer and be done with it, because for what it's going to cost him to do it he said it's not worth it" and farmer B6, "I don't think most vets look forward to come out if you tell them it's a hoof."

Farmers did appreciate that advisors travel to multiple farms and could learn and share what other farms have tried and what had worked. This knowledge was particularly valued for its practicality, as it came from other farmers experiencing similar problems and constraints. For example, farmer D6 said, "Sometimes, just having them-someone like the vet, who's been to umpteen different farms. And if you're willing to listen to them, and ask them, what do you see that could be done? Probably be one of the best things you could do." However, though the majority of farmers worked with a veterinarian and hoof trimmer in some capacity, facilitated collaboration between veterinarians and hoof trimmers was limited. For example, farmer C2 said,
"We work with the veterinarian and we work with the hoof trimmer, but not together."

Advisors' Expectations of Farmers. While advisors expected farmers to take responsibility for lameness and proactively work toward solutions, they also appreciated that farmers faced barriers in lameness management, particularly related to time, money, and labor resources. As shared by veterinarian B6, "They [farmers] have X amount of time and they're going to put it where they think they can see those - it's probably up to me to be as much proactive and say, "well, you can gain a lot by this' and keep hammering it home.... It still ends up being their decision where they're going to put their time and effort and what time they've got." Advisors empathized with the workload of farmers and understood that making a management change may be low priority if a farm was struggling financially or otherwise, as hoof trimmer C4 shared, "I see too some of my managers are just so overworked, and they don't realize it, but you can't give from a cup that's half full. So then when we go and have suggestions or try to get a moment of their time to explain or talk about the day... it's not there."

At the same time, advisors were also frustrated due to their view of farmers as a key bottleneck in lameness management. Advisors reported running into farmerlevel barriers, such as giving advice that is not listened to or farmers who are resistant to change. For example, veterinarian E5 commented, "You get kind of tired of seeing the same thing over and over again and nothing changes... It's frustrating." Many felt that, ultimately, the decisions on the farm come down to the farmer and there is only so much advisors can do. For example, hoof trimmer C5 said, "Like everybody has said, we can pick them out. We can talk to them. We can try to teach them. We can try to do as much as we want, but at the end of the day it's still their herd of cows and it's our business to come into their herd, do our job."

Some hoof trimmers wanted to be more involved in management decisions around lameness control. Hoof trimmer A5 said, "Sometimes I don't think farmers give enough respect to the hoof trimmers, that [we] can help in things besides wrapping a foot or blocking it." This was also described by hoof trimmer $\mathrm{C} 4$ as a desire to be included in management meetings with farmers and their advisors, "I think everybody that trims feet needs to push to be a part of those meetings because if we can learn what's going on and the reality is too...you're probably on that farm just as much as anyone else in that meeting."

Advisors' Expectations of Other Advisors. Advisors acknowledged that veterinarians and hoof trimmers have different technical roles in lameness management and that their people-focused consultative roles 
overlap considerably. Advisor discussions encompassed both the negative (potential for conflict) and positive aspects of working together (being on the same page, alignment in recommendations and goals).

While advisors ideally wished for goal alignment and collaboration between hoof trimmers and veterinarians, many expressed uncertainties about the degree to which they should "stay in their own lane." This uncertainty hindered their confidence in trying to reach out to collaborate cohesively, as veterinarian C4 said, "I think it [veterinarians asking hoof trimmers about hoof health] is probably in the same room as the hoof trimmer asking us about repro[duction] protocols. We'd probably get defensive about the same thing because that's what we're very good at. So it's just how comfortable are you with what you know... Are you willing to work with them, or are you going to be reserved and stay-in-your-lane mentality?"

Compounding the difficulty of establishing collaborative relationships, many advisors were critical of others' knowledge, education, and intentions relative to lameness management. While some advisors acknowledged the variation among individuals (for example, hoof trimmer A5 said, "I think veterinarians are about as diverse as hoof trimmers. You've got some that want hands on with you and are there.... Then you have others that tell their clients, 'Call a hoof trimmer' [and] ...others that don't want anything to do with you period"), a common refrain among both veterinarians and hoof trimmers was skepticism of others' expertise. For example, hoof trimmer A5 shared, "I think hoof trimmers know more on the foot than a vet. That's not degrading vets because they have to look at a lot more than we do. I think we have to work together and vets have to respect hoof trimmers in that regard and most of them do. If they don't, I think they should because we do have some expertise in that area." Some hoof trimmers wanted veterinarians to prioritize lameness management to a greater extent than they were perceived to do. Hoof trimmer B9 said, "What I don't understand is these veterinarians coming into these herds for herd health quite a bit, and they see all these lame cows and rarely do I see them telling the farms you should maybe trim a few more cows...." In contrast, some veterinarians were dismissive toward hoof trimmers: for example, veterinarian E6 said, "Yeah, with the hoof trimmers, we've all gone to graduate school. We're all professionals, we've been trained. So, when you deal with hoof trimmers and the relationship with them, I mean, they've gone to training, they've done that. Not to the level that we have, but are they taking their knowledge or are they just coming out there and trimming feet and trying to put as many wraps and blocks on as possible to dollar up the bill?"
Though advisors clearly expressed barriers in working collaboratively on lameness management, not all discussion was focused on complaints. Advisors also commonly expressed their desire to work together and their hope for improved relationships built upon mutual respect. For example, hoof trimmer A6 shared that, "I think the vets are actually learning too, that the hoof trimmers are a major role.... They actually work with us more, but they also recognize our profession is educated more on that than the vets, especially the schools we go in and teach at, they respect us just as much as we respect them." Veterinarian E5 summarized this as well, stating, "I think hoof trimmers respond well too if you come at it as a team approach. I'm not better than you, I'm not superior, my knowledge isn't superior...the struggles that I'm having in having the conversations with the producers are the same exact ones that they're having. And so, if we can kind of brainstorm what is the number one concern? What should we kind of address together and approach the producer together as how to do this? Sometimes two voices are better than one."

The ability to deliver a consistent message through collaboration was particularly compelling, with some sharing examples of past successes through this approach. For example, veterinarian B6 said, "I think with the more communication you have with the hoof trimmer, you get more of a pulse of what's actually going on in the dairy." Similarly, hoof trimmer D7 reported a successful collaboration with a veterinarian: "I work with one vet...if he sees something, he'll shoot me a text and he'll say, 'Hey, I'm kind of seeing this. Are you seeing anything on your end?' Or vice versa." Finally, participants emphasized the importance of communication, as hoof trimmer $\mathrm{C} 4$ said, "If we can all talk with each other, we can deliver a consistent and concise - most importantly concise-message to the farmer."

\section{DISCUSSION}

The goal of this work was to explore perceptions of lameness and barriers to improved lameness management among dairy farmers, hoof trimmers, and veterinarians. The results of this study highlight the complexities of managing lameness, the barriers stakeholders face, and stakeholders' perceptions of their own role and their expectations of others in lameness management.

\section{Perceptions and Barriers of Lameness Management}

Participants discussed barriers that apply to the management of many diseases in dairy cattle, including 
time, money, and facility limitations. These physical resource barriers have been well characterized related to the management of lameness (Leach et al., 2010; Dutton-Regester et al., 2019) as well as other dairy cow diseases (for example, Johne's disease; Roche et al., 2019). Participants also discussed challenges that were specific to lameness, such as having no way to easily monitor lameness, dealing with multiple lesion types with different causes, and having control measures that can be difficult to implement. In addition, because lameness can be chronic, it may take a long time to see a benefit of a control measure. Participants also observed that the costs of lameness are indirect and can be difficult to observe, particularly when compared with more apparent direct costs (e.g., milk down the drain in the case of mastitis). Though the cost may be difficult to observe, lameness is clearly costly (Bruijnis et al., 2010; Dolecheck et al., 2019). Making farmers aware of these costs is one approach to improve motivation, though cost effectiveness is only one of many factors that farmers weigh when considering management changes (Ritter et al., 2017).

Despite the many challenges faced in lameness management, some farms manage lameness successfully and have few lame cows. Lameness prevalence varies widely (from 3\% to 80\%; von Keyserlingk et al., 2012; Cook et al., 2016). This wide range in lameness prevalence was echoed by our participants, as advisors discussed large farm-to-farm variation in lameness issues. Advisors viewed differences in farm facilities, the management attention that lameness received, and farmer mindset as reasons for the variation they saw in lameness prevalence. This observation by our participants is supported by literature emphasizing the importance of housing and housing management (Chapinal et al., 2013; Adams et al., 2017) and farmer perception and prioritization (Leach et al., 2010; Bruijnis et al., 2012).

An important finding from this study is that advisors described experiencing normalization of lameness, (i.e., that lameness can become commonplace on farms and not recognized by farmers). Acceptance of a certain level of disease by stakeholders on farms has been previously documented (Tremetsberger and Winckler, 2015; Sumner et al., 2018). Croyle et al. (2019) described this issue as "barn blindness," defined as a lack of perception of problems in one's own herd. Multiple diseases and welfare issues can become normalized, but this challenge may be particularly relevant for lameness management, as the primary way to diagnose lame cows is through visual observation. The lack of objective lameness detection methods may play a role in normalization, as farmers, hoof trimmers, and veterinarians may have different definitions for what lameness looks like and when a cow may benefit from treatment. Farmers have been shown to underestimate lameness on their herd (Espejo et al., 2006; Higginson Cutler et al., 2017), but it has been hypothesized the difference may be due to differing definitions of lameness among different stakeholders, with farmers looking at the balance of evidence over weeks and months and considering cow history, whereas trained assessors examined a one-time visual locomotion score (Eriksson et al., 2020). Farmers may also use different language to describe lame cows, for example using "impaired mobility" rather than "mildly lame" (Horseman et al., 2014). Though we did not specifically ask our participants to explain their definition of lameness, advisors did point to different definitions between farmers and advisors as a barrier. Both differing definitions and normalization may slow changes in lameness management, as farmers cannot change an issue that is not seen or recognized. Both farmer and advisor participants noted this area offers a role for advisors: to notice and bring attention to lameness issues going unseen by the farmer. However, it is likely advisors can also become accustomed to seeing lameness, as veterinarians have also been shown to underestimate lameness (Denis-Robichaud et al., 2020). Opportunities to better identify and monitor lameness on herds include emerging technologies to offer objective assessments (Alsaaod et al., 2019), routine training for more consistent assessments (Croyle et al., 2018), and benchmarking (von Keyserlingk et al., 2012).

The complexity and magnitude of the lameness problem on their farms appeared to leave some farmer participants with a feeling of inevitability. This described feeling of resignation to the inevitability of lameness may result in ambivalence toward making changes focused on lameness or allow complacency to develop. This may affect farmers' willingness to adopt recommendations for improvement. The theory of planned behavior (TPB) is a psycho-social framework that may provide some context for this finding. The TPB has been used to predict behavioral intention or the readiness to perform a given behavior (Ajzen, 1991) and emphasizes the role of perceived control over the performance of the behavior (perceived ease or difficulty in performing the behavior). The more barriers to controlling lameness one perceives, the lower one's level of perceived behavioral control. Control beliefs are based on past experiences, the presence of needed resources, secondhand experience, and perceived barriers (Ajzen, 1991). In our study, farmers who discussed digital dermatitis lesions as the biggest cause of lameness on their farms also reported that the barriers to improved control were very high (e.g., difficulties in running a footbath, the cost of treatment, and difficulties in changing manure management). These barriers may lead to low perceived behavioral control and a low willingness to adopt rec- 
ommendations for improvement. It should be noted that TPB has been criticized for its focus on framing individuals as sole actors and external factors (e.g., cultural, regulatory, interpersonal) as being important to the extent that they influence the individual (Shortall et al., 2016). Further work should continue integrating the individual, interpersonal, and contextual barriers. Previous research has shown the barriers that farmers face in reducing lameness on their herds include low detection, a high tolerance of lameness, lack of awareness of the welfare impact of lameness, and other herd health issues being given priority (Leach et al., 2010; Sadiq et al., 2019). As our understanding of these barriers increases, more attention must be paid to developing tailored interventions to address these specific barriers and support farmers and advisors in adapting or changing existing lameness management practices.

\section{Roles of Stakeholders}

Multiple stakeholders are involved in lameness management and hence we chose to include farmers, hoof trimmers, and veterinarians in our study. Engaging multiple stakeholders is needed to create and support partnerships and ensure long-term viability of organizations, plans, and programs (Bryson, 2004). Our participants described how the tasks and management of lameness were shared by farmers, hoof trimmers, veterinarians, farm staff, nutritionists, and others. These different stakeholders bring unique insights into issues and solutions, and we can harness this to improve lameness management.

Advisors discussed their role in lameness management as 3-fold: technical, advisory, and animal advocates. These areas overlap and within a single interaction they may navigate all 3 . Though not all advisors brought up animal welfare, some of our participants felt very strongly about their role in improving welfare and pushing farmers for improved welfare practices. They discussed emphasizing the poor welfare caused by lameness as a way to encourage farmers to see lameness management as a priority. Several hoof trimmer participants described a choice to use the language of pain and suffering when pushing farmers to make a lameness management improvement. Studies have demonstrated that farmers consider pain and suffering of lame cows as a motivating factor for making on-farm changes (Leach et al., 2010; Croyle et al., 2019), though lameness, particularly mild cases, is not universally considered by farmers to be painful (Bruijnis et al., 2013). More work is needed to better understand welfare as a motivating factor with respect to lameness management.

The role of the veterinarian within health management has been discussed, often through the lens of a shifting role, from offering medical care to individual animals to a more consultative role (LeBlanc et al., 2006). Veterinarians are trusted sources of information, both on health and welfare (Ritter et al., 2017). Both veterinarians and hoof trimmer participants saw a role for veterinarians to be more involved in lameness management, which aligns with our farmer participants largely reporting that veterinarians were not involved in lameness management on their farms. The treatment of certain hoof lesions can be considered a medical procedure and veterinarians can be further involved in developing treatment protocols, especially for lesions that require antimicrobials and pain control. Veterinary involvement is not an area for improvement limited to lameness. Mills et al. (2020) found veterinarian involvement in transition period management could be improved and increased access to veterinary advice has been shown to be beneficial in managing Johne's disease and improving calf welfare (Ritter et al., 2015; Sumner et al., 2020). One intervention has demonstrated that increased veterinarian or advisor involvement improved lameness outcomes (Main et al., 2012; Whay et al., 2012). Taken together with previous work, our findings point to the need for further involving veterinarians in both individual animal and herd-level lameness management strategies on farms.

Hoof trimmers also have an important role in lameness management, though little research has included hoof trimmers beyond collecting lesion or billing data (Solano et al., 2016; Dolecheck et al., 2018). Becker et al. $(2013,2014)$ surveyed Swiss hoof trimmers on their attitudes toward painful therapeutic hoof trimming of dairy cattle. Participants in our study described hoof trimmers as very commonly used and relied upon for lesion detection and treatment. Participants additionally described hoof trimmers as valued and trusted sources of lameness management information and advice. Croyle et al. (2019) similarly reported that farmers trusted hoof trimmers and held their opinions and recommendations in high regard. Furthermore, both our farmer and veterinarian participants largely placed the responsibility of complex lesion treatments on hoof trimmers. Due to their clear importance as advisors in lameness management, there is an opportunity to increase collaboration between hoof trimmers and other lameness management stakeholders, as well as further include hoof trimmers in lameness research and extension activities beyond data collection.

\section{The Need for Increased Stakeholder Collaboration}

In this study, participants spoke about success stories of working together, and how the match of a farmer with a skilled and invested advisor can lead to ben- 
eficial changes. Participants discussed valuing being part of a team, both in an acknowledgment that the task of lameness management cannot be done alone, but also that multiple voices can provide ideas, motivation, and support. Lameness research from the Healthy Feet Programme in the United Kingdom showed some evidence that collaboration between advisors and farmers can reduce the prevalence of lameness (Main et al., 2012). Increased dairy farmer-veterinarian cooperation has been shown to be beneficial in other areas of dairy health management (Ritter et al., 2015; Sumner et al., 2020). Collectively, this work suggests cooperation between these stakeholders is key to improving lameness management.

Stakeholder collaboration is not without potential areas of disagreement and conflict. Bell et al. (2009) highlights that a multi-stakeholder collaboration in lameness management can indeed fail, though the reasons that program did not succeed are unclear. The conflicts described by our participants appeared to stem from expectations of one another that were sometimes unfulfilled. For example, advisor participants described unmet expectations of farmers, viewing farmers as a bottleneck in lameness management and wanting farmers to take their advice and make changes. Advisors who feel this is a barrier may need to tailor their communication approach to individual clients. Lam et al. (2011) described that effective communication with farmers must take into account different learning preferences, be proactive and realistic, and offer personalized messages. Advisor participants also reported conflicts with other advisors over differing expectations of roles and responsibilities. Advisor conflicts can be further complicated by their different commercial interests. As we continue to explore how to develop stakeholder teams with unified goals, farmers can and likely need to be the champions of the team approach as they are paying these independent advisors. That said, advisors should bring ideas to the table in an effort to be proactive and have more impact. Future work on improving lameness management on dairy farms should explore specific strategies to improve stakeholder collaboration.

\section{Limitations}

In our data collection and analyses we used wellestablished methodological approaches to ensure the validity of results. We offer evidence of transparency and quality through descriptions of methods, researcher reflexivity, collaboration, peer debriefing, and rich descriptions of our themes (Creswell and Miller, 2000). Although this study offers many insights into stakeholder perceptions and experiences with lameness management, it has several limitations. The majority of discussion was based around barriers and challenges in lameness management, a result of our problem-centric research approach (Boyd and Bright, 2007). We framed lameness as a problem in need of solving and questions were more focused on understanding participants' perceptions of difficulties rather than successes. Our themes are thus representative of our focus group discussions and we acknowledge that a different framing on positives, successes, and motivators would yield different responses.

We recruited the majority of our participants at meetings, conferences, and workshops. It is possible that they were more informed on the topic of lameness or more progressive in their thinking than stakeholders who do not typically attend these types of events. Wherever possible we held our focus groups before the conference or workshop programming, but in 8 instances the timing of groups was outside our control. This is a limitation, as participants may have been exposed to conference or meeting information on lameness and hence may have been primed to focus on certain topics. However, we do not believe this to be a large source of bias because the question guides encouraged participants to focus on their own experiences. Additionally, for a single hoof trimmer focus group (in NY) we recruited participants from a national conference, and therefore the hoof trimmer participants were from a wider geographic area than other participants. However, upon analysis the participant experiences in this group aligned with the themes found among our other groups, and so we elected to include them in this report.

We also recruited veterinarians who practiced at the same clinic and we might expect some of their thoughts to be clustered by clinic, as they may have talked about lameness management as a clinic or have taken continuing education programming together. That said, veterinarians have their own clients and their own unique experiences, and they have formed their own opinions and views on challenges and best practices. We also had 2 veterinarians who participated in 2 different groups; this was allowed in one instance to benefit the participant and in the second it was not noticed until after the group had finished. We note that these individuals did not dominate the discussions and that effort was made to ensure that the codes and themes resulting from analysis were representative of all focus groups.

\section{CONCLUSIONS}

Dairy farmer, hoof trimmer, and veterinarian participants in this study viewed lameness as a highly complex management challenge. Participants highlighted that multiple stakeholders have a role in lameness manage- 
ment and found lameness to be a shared responsibility on a dairy farm. Increasing farmer, hoof trimmer, and veterinarian communication and collaboration in making decisions may help achieve improvements in lameness management.

\section{ACKNOWLEDGMENTS}

The authors thank the participants for contributing to this study, as well as all who helped in arranging focus groups. This work was supported by the Minnesota State Legislature through the Rapid Agricultural Response Fund managed by the Minnesota Agricultural Experiment Station (St. Paul). The authors have not stated any conflicts of interest.

\section{REFERENCES}

Adams, A. E., J. Lombard, C. Fossler, I. Román-Muñiz, and C. Kopral. 2017. Associations between housing and management practices and the prevalence of lameness, hock lesions, and thin cows on US dairy operations. J. Dairy Sci. 100:2119-2136. https://doi .org/10.3168/jds.2016-11517.

Ajzen, I. 1991. The theory of planned behavior. Organ. Behav. Hum. Decis. Process. 50:179-211. https://doi.org/10.1016/0749 -5978(91)90020-T.

Alsaaod, M., M. Fadul, and A. Steiner. 2019. Automatic lameness detection in cattle. Vet. J. 246:35-44. https://doi.org/10.1016/j .tvj1.2019.01.005.

Archer, S. C., M. J. Green, and J. N. Huxley. 2010. Association between milk yield and serial locomotion score assessments in UK dairy cows. J. Dairy Sci. 93:4045-4053. https://doi.org/10.3168/ jds.2010-3062.

Becker, J., M. Reist, K. Friedli, D. Strabel, M. Wüthrich, and A. Steiner. 2013. Current attitudes of bovine practitioners, claw-trimmers and farmers in Switzerland to pain and painful interventions in the feet in dairy cattle. Vet. J. 196:467-476. https://doi.org/10.1016/ j.tvjl.2012.12.021.

Becker, J., M. Reist, and A. Steiner. 2014. Factors influencing the attitudes of cattle veterinarians, farmers, and claw trimmers towards the pain associated with the treatment of sole ulcers and the sensitivity to pain of dairy cows. Vet. J. 200:38-43. https://doi.org/ 10.1016/j.tvjl.2014.01.016.

Bell, N. J., M. J. Bell, T. G. Knowles, H. R. Whay, D. J. Main, and A. J. F. Webster. 2009. The development, implementation and testing of a lameness control programme based on HACCP principles and designed for heifers on dairy farms. Vet. J. 180:178-188. https:// doi.org/10.1016/j.tvjl.2008.05.020.

Berkwits, M., and T. Inui. 1998. Making use of qualitative research techniques. J. Gen. Intern. Med. 13:195-199. https://doi.org/10 $.1046 /$ j.1525-1497.1998.00054.x.

Bicalho, R. C., F. Vokey, H. N. Erb, and C. L. Guard. 2007. Visual locomotion scoring in the first seventy days in milk: Impact on pregnancy and survival. J. Dairy Sci. 90:4586-4591. https://doi .org/10.3168/jds.2007-0297.

Birks, M., Y. Chapman, and K. Francis. 2008. Memoing in qualitative research: Probing data and processes. J. Res. Nurs. 13:68-75. https://doi.org/10.1177/1744987107081254.

Booth, C. J., L. D. Warnick, Y. T. Gröhn, D. O. Maizon, C. L. Guard, and D. Janssen. 2004. Effect of lameness on culling in dairy cows. J. Dairy Sci. 87:4115-4122. https://doi.org/10.3168/jds.S0022 -0302(04)73554-7.

Boyd, N. M., and D. S. Bright. 2007. Appreciative inquiry as a mode of action research for community psychology. J. Community Psychol. 35:1019-1036. https://doi.org/10.1002/jcop.20208.
Braun, V., and V. Clarke. 2006. Using thematic analysis in psychology. Qual. Res. Psychol. 3:77-101. https://doi.org/10.1191/ 1478088706qp063oa.

Bruijnis, M., H. Hogeveen, C. Garforth, and E. Stassen. 2013. Dairy farmers' attitudes and intentions towards improving dairy cow foot health. Livest. Sci. 155:103-113. https://doi.org/10.1016/j.livsci .2013.04.005.

Bruijnis, M. R. N., B. Beerda, H. Hogeveen, and E. N. Stassen. 2012. Foot disorders in dairy cattle: Impact on cow and dairy farmer. Anim. Welf. 21:33-40. https://doi.org/10.7120/ $096272812 X 13345905673601$.

Bruijnis, M. R. N., H. Hogeveen, and E. N. Stassen. 2010. Assessing economic consequences of foot disorders in dairy cattle using a dynamic stochastic simulation model. J. Dairy Sci. 93:2419-2432. https://doi.org/10.3168/jds.2009-2721.

Bryson, J. M. 2004. What to do when stakeholders matter: Stakeholder identification and analysis techniques. Public Manage. Rev. 6:21-53. https://doi.org/10.1080/14719030410001675722.

Chapinal, N., A. K. Barrientos, M. A. G. von Keyserlingk, E. Galo, and D. M. Weary. 2013. Herd-level risk factors for lameness in freestall farms in the northeastern United States and California. J. Dairy Sci. 96:318-328. https://doi.org/10.3168/jds.2012-5940.

Clarke, V., and V. Braun. 2013. Successful Qualitative Research: A Practical Guide for Beginners. SAGE Publications.

Cook, N. B., J. P. Hess, M. R. Foy, T. B. Bennett, and R. L. Brotzman. 2016. Management characteristics, lameness, and body injuries of dairy cattle housed in high-performance dairy herds in Wisconsin. J. Dairy Sci. 99:5879-5891. https://doi.org/10.3168/jds.2016 $-10956$.

Creswell, J. W., and D. L. Miller. 2000. Determining validity in qualitative inquiry. Theory Pract. 39:124-130. https://doi.org/10.1207/ s15430421tip3903_2.

Croyle, S. L., E. Belage, D. K. Khosa, S. J. LeBlanc, D. B. Haley, and D. F. Kelton. 2019. Dairy farmers' expectations and receptivity regarding animal welfare advice: A focus group study. J. Dairy Sci. 102:7385-7397. https://doi.org/10.3168/jds.2018-15821.

Croyle, S. L., C. G. R. Nash, C. Bauman, S. J. LeBlanc, D. B. Haley, D. K. Khosa, and D. F. Kelton. 2018. Training method for animalbased measures in dairy cattle welfare assessments. J. Dairy Sci. 101:9463-9471. https://doi.org/10.3168/jds.2018-14469.

Denis-Robichaud, J., D. Kelton, V. Fauteux, M. Villettaz-Robichaud, and J. Dubuc. 2020. Short communication: Accuracy of estimation of lameness, injury, and cleanliness prevalence by dairy farmers and veterinarians. J. Dairy Sci. 103:10696-10702. https://doi.org/ 10.3168 /jds.2020-18651.

Denzin, N. K., and Y. S. Lincoln. 2000. The SAGE Handbook of Qualitative Research. SAGE Publications.

Dolecheck, K., and J. Bewley. 2018. Animal board invited review: Dairy cow lameness expenditures, losses and total cost. Animal 12:1462-1474. https://doi.org/10.1017/S1751731118000575.

Dolecheck, K. A., R. M. Dwyer, M. W. Overton, and J. M. Bewley. 2018. A survey of United States dairy hoof care professionals on costs associated with treatment of foot disorders. J. Dairy Sci 101:8313-8326. https://doi.org/10.3168/jds.2018-14718.

Dolecheck, K. A., M. W. Overton, T. B. Mark, and J. M. Bewley. 2019. Use of a stochastic simulation model to estimate the cost per case of digital dermatitis, sole ulcer, and white line disease by parity group and incidence timing. J. Dairy Sci. 102:715-730. https:/ /doi.org/10.3168/jds.2018-14901.

Driessen, C. 2012. Farmers engaged in deliberative practices; An ethnographic exploration of the mosaic of concerns in livestock agriculture. J. Agric. Environ. Ethics 25:163-179. https://doi.org/10 .1007/s10806-010-9293-z.

Dutton-Regester, K. J., J. D. Wright, A. R. Rabiee, and T. S. Barnes. 2019. Understanding dairy farmer intentions to make improvements to their management practices of foot lesions causing lameness in dairy cows. Prev. Vet. Med. 171:104767. https://doi.org/10 .1016/j.prevetmed.2019.104767.

Eriksson, H. K., R. R. Daros, M. A. G. von Keyserlingk, and D. M. Weary. 2020. Effects of case definition and assessment frequency 
on lameness incidence estimates. J. Dairy Sci. 103:638-648. https: //doi.org/10.3168/jds.2019-16426.

Espejo, L. A., M. I. Endres, and J. A. Salfer. 2006. Prevalence of lameness in high-producing Holstein cows housed in freestall barns in Minnesota. J. Dairy Sci. 89:3052-3058. https://doi.org/10.3168/ jds.S0022-0302(06)72579-6.

Groenevelt, M., D. C. J. Main, D. Tisdall, T. G. Knowles, and N. J. Bell. 2014. Measuring the response to therapeutic foot trimming in dairy cows with fortnightly lameness scoring. Vet. J. 201:283-288. https://doi.org/10.1016/j.tvjl.2014.05.017.

Higginson Cutler, J. H., J. Rushen, A. M. de Passillé, J. Gibbons, K. Orsel, E. Pajor, H. W. Barkema, L. Solano, D. Pellerin, D. Haley, and E. Vasseur. 2017. Producer estimates of prevalence and perceived importance of lameness in dairy herds with tiestalls, freestalls, and automated milking systems. J. Dairy Sci. 100:98719880. https://doi.org/10.3168/jds.2017-13008.

Holmes, A. G. D. 2020. Researcher positionality - A consideration of its influence and place in qualitative research - A new researcher guide. Shanlax Int. J. Educ. 8:1-10.

Horseman, S., E. Roe, J. Huxley, N. Bell, C. Mason, and H. Whay 2014. The use of in-depth interviews to understand the process of treating lame dairy cows from the farmers' perspective. Anim. Welf. 23:157-165. https://doi.org/10.7120/09627286.23.2.157.

Hulsen, J. 2011. Hoof Signals: Success Factors for Healthy Hooves. Cow signals. Roodbont.

Kleinhenz, K. E., P. J. Plummer, J. Danielson, R. G. Burzette, P. J. Gorden, J. Coetzee, J. A. Schleining, V. Cooper, B. Leuschen, A. Krull, L. Shearer, and J. K. Shearer. 2014. Survey of veterinarians and hoof trimmers on methods applied to treat claw lesions in dairy cattle. Bov. Pract. 48:47-52.

Krueger, R. A., and M. A. Casey. 2015. Focus Groups: A Practical Guide for Applied Research. SAGE Publications.

Lam, T. J., J. Jansen, B. H. van den Borne, R. J. Renes, and H. Hogeveen. 2011. What veterinarians need to know about communication to optimise their role as advisors on udder health in dairy herds. N. Z. Vet. J. 59:8-15. https://doi.org/10.1080/00480169 .2011.547163.

Leach, K. A., H. R. Whay, C. M. Maggs, Z. E. Barker, E. S. Paul, A. K. Bell, and D. C. J. Main. 2010. Working towards a reduction in cattle lameness: 2. Understanding dairy farmers' motivations. Res. Vet. Sci. 89:318-323. https://doi.org/10.1016/j.rvsc.2010.02.017.

LeBlanc, S. J., K. D. Lissemore, D. F. Kelton, T. F. Duffield, and K. E. Leslie. 2006. Major advances in disease prevention in dairy cattle. J. Dairy Sci. 89:1267-1279. https://doi.org/10.3168/jds.S0022 -0302(06)72195-6.

Main, D. C. J., K. A. Leach, Z. E. Barker, A. K. Sedgwick, C. M. Maggs, N. J. Bell, and H. R. Whay. 2012. Evaluating an intervention to reduce lameness in dairy cattle. J. Dairy Sci. 95:2946-2954. https://doi.org/10.3168/jds.2011-4678.

Maxwell, J. A. 2012. A Realist Approach for Qualitative Research. SAGE Publications.

Mills, K. E., D. M. Weary, and M. A. G. von Keyserlingk. 2020. Identifying barriers to successful dairy cow transition management. J. Dairy Sci. 103:1749-1758. https://doi.org/10.3168/jds.2018-16231.

Minnesota Department of Agriculture. 2021. Dairy Farm Activity Report. Accessed Mar. 3, 2021. https://www.mda.state.mn.us/food -feed/dairy-minnesota.

Murray, R. D., D. Y. Downham, M. J. Clarkson, W. B. Faull, J. W. Hughes, F. J. Manson, J. B. Merritt, W. B. Russell, J. E. Sutherst, and W. R. Ward. 1996. Epidemiology of lameness in dairy cattle: Description and analysis of foot lesions. Vet. Rec. 138:586-591. https://doi.org/10.1136/vr.138.24.586.

National Dairy FARM Program. 2021. FARM Program Animal Care Participation Statistics. Accessed March 12, 2021. https:// nationaldairyfarm.com.

Ritter, C., J. Jansen, S. Roche, D. F. Kelton, C. L. Adams, K. Orsel, R. J. Erskine, G. Benedictus, T. J. G. M. Lam, and H. W. Barkema. 2017. Invited review: Determinants of farmers' adoption of management-based strategies for infectious disease prevention and control. J. Dairy Sci. 100:3329-3347. https://doi.org/10.3168/ jds.2016-11977.
Ritter, C., G. P. S. Kwong, R. Wolf, C. Pickel, M. Slomp, J. Flaig, S. Mason, C. L. Adams, D. F. Kelton, J. Jansen, J. De Buck, and H. W. Barkema. 2015. Factors associated with participation of Alberta dairy farmers in a voluntary, management-based Johne's disease control program. J. Dairy Sci. 98:7831-7845. https://doi .org $/ 10.3168 /$ jds.2015-9789.

Roche, S. M., D. Kelton, M. Meehan, M. Von Massow, and A. JonesBitton. 2019. Exploring dairy producer and veterinarian perceptions of barriers and motivators to adopting on-farm management practices for Johne's disease control in Ontario, Canada. J. Dairy Sci. 102:4476-4488. https://doi.org/10.3168/jds.2018-15944.

Sadiq, M. B., S. Ramanoon, W. Shaik Mossadeq, R. Mansor, and S. Syed Hussain. 2019. Dairy farmers' perceptions of and actions in relation to lameness management. Animals (Basel) 9:270. https:// doi.org/10.3390/ani9050270.

Shock, D. A., J. B. Coe, S. J. LeBlanc, K. E. Leslie, D. Renaud, S. Roche, K. Hand, M. A. Godkin, and D. F. Kelton. 2020. Characterizing the attitudes and motivations of Ontario dairy producers toward udder health. J. Dairy Sci. 103:4618-4632. https://doi.org/ $10.3168 /$ jds.2019-16621.

Shortall, O., A. Ruston, M. Green, M. Brennan, W. Wapenaar, and J. Kaler. 2016. Broken biosecurity? Veterinarians' framing of biosecurity on dairy farms in England. Prev. Vet. Med. 132:20-31. https: //doi.org/10.1016/j.prevetmed.2016.06.001.

Solano, L., H. W. Barkema, S. Mason, E. A. Pajor, S. J. LeBlanc, and K. Orsel. 2016. Prevalence and distribution of foot lesions in dairy cattle in Alberta, Canada. J. Dairy Sci. 99:6828-6841. https://doi .org/10.3168/jds.2016-10941.

Sumner, C. L., M. A. G. von Keyserlingk, and D. M. Weary. 2018. Perspectives of farmers and veterinarians concerning dairy cattle welfare. Anim. Front. 8:8-13. https://doi.org/10.1093/af/vfx006.

Sumner, C. L., M. A. G. von Keyserlingk, and D. M. Weary. 2020. How benchmarking promotes farmer and veterinarian cooperation to improve calf welfare. J. Dairy Sci. 103:702-713. https://doi.org/ $10.3168 /$ jds.2019-16338.

Thomas, H. J., G. G. Miguel-Pacheco, N. J. Bollard, S. C. Archer, N. J. Bell, C. Mason, O. J. R. Maxwell, J. G. Remnant, P. Sleeman, H. R. Whay, and J. N. Huxley. 2015. Evaluation of treatments for claw horn lesions in dairy cows in a randomized controlled trial. J. Dairy Sci. 98:4477-4486. https://doi.org/10.3168/jds.2014-8982.

Tremetsberger, L., and C. Winckler. 2015. Effectiveness of animal health and welfare planning in dairy herds: A review. Anim. Welf. 24:55-67. https://doi.org/10.7120/09627286.24.1.055.

USDA. 2018. Dairy 2014. Health and Management Practices on U.S. Dairy Operations, 2014.

USDA. 2021. USDA's National Agricultural Statistics Service Wisconsin Field Office. Accessed Mar. 3, 2021. https://www.nass.usda .gov/Statistics_by_State/Wisconsin/.

Ventura, B. A., M. A. G. von Keyserlingk, and D. M. Weary. 2015. Animal welfare concerns and values of stakeholders within the dairy industry. J. Agric. Environ. Ethics 28:109-126. https://doi.org/10 $.1007 / \mathrm{s} 10806-014-9523-\mathrm{x}$.

von Keyserlingk, M. A. G., A. Barrientos, K. Ito, E. Galo, and D. M. Weary. 2012. Benchmarking cow comfort on North American freestall dairies: Lameness, leg injuries, lying time, facility design, and management for high-producing Holstein dairy cows. J. Dairy Sci. 95:7399-7408. https://doi.org/10.3168/jds.2012-5807.

Whay, H. R., Z. E. Barker, K. A. Leach, and D. C. J. Main. 2012. Promoting farmer engagement and activity in the control of dairy cattle lameness. Vet. J. 193:617-621. https://doi.org/10.1016/j .tvjl.2012.06.041.

\section{ORCIDS}

E. M. Wynands () https://orcid.org/0000-0002-7916-7959

S. M. Roche (1) https://orcid.org/0000-0001-6934-6497

G. Cramer $\odot$ https://orcid.org/0000-0003-2691-3417

B. A. Ventura @ https://orcid.org/0000-0001-9476-6901 


\section{APPENDIX}

Focus group question guide to elicit attitudes and perceptions about lameness, barriers in lameness management, perceptions of one's own role in lameness, and expectations of others. Questions were modified slightly for farmer, veterinarian, and hoof trimmer groups.

\section{Perceptions of Importance and Prevalence of Lameness in the Dairy Industry}

1. I'd like to start out by getting your opinions on lameness in the dairy industry. How big of a challenge do you think it is, is it a challenge at all, if so, where would you rank it against other cow health and well-being challenges?

2. What's your personal experience dealing with lame cattle?

3. Do you find a range; why do you think it's better or worse on some farms than others?

\section{Lameness Management: Perceptions of Barriers}

1. What, if any, barriers do you find yourself facing with regard to lameness?

2. Let them take on prevention and treatment, and depending on the conversation, recap, "so what
I've heard from you is that you really see issues with lameness prevention. Can you also speak to your views on treatment?"

3. Probes: What about at the herd level?

\section{Role in Lameness Management, Role of Other Stakeholders}

1. How do you see your role, if any, in contributing to lameness management? What do you view your role is in lameness control?

2. Do you think anyone else has important roles to play?

3. Do you have an active relationship with a veterinarian/hoof trimmer? Can you tell me more about that? Probe: why is that relationship valuable or challenging? If you did have this relationship, what would you find valuable or challenging?

4. Have you previously approached any advisors about a lameness issue? Can you share the steps you took? Were you satisfied with the outcome? Why/why not? Let's say you approach an advisor about a lameness issue, what would you envision happening? 